\title{
The interaction of vitamin A deficiency and rotavirus infection in the mouse
}

\author{
BY FARUK AHMED ${ }^{1}$, DAVID B. JONES ${ }^{2}$ AND ALAN A. JACKSON"* \\ ${ }^{1}$ Department of Human Nutrition, ${ }^{2}$ Department of Pathology, University of Southampton, \\ Bassett Crescent East, Southampton SO9 3TU
}

(Received 20 February 1989 - Accepted 27 October 1989)

\begin{abstract}
Weanling mice were fed on a control diet ad lib., a vitamin A-deficient diet ad lib. or pair-fed to the intake of the vitamin A-deficient group. Vitamin A deficiency was induced by 63-70 d of age. On day 77 mice were given $30 \mu \mathrm{l}$ rotavirus/mouse orally and examined histologically 1 week later. There were no changes in relative liver weight in any of the groups, but following infection animals deficient in vitamin $A$ showed a significant increase in spleen weight compared with the other groups. The relative weight of the thymus was reduced by vitamin A deficiency, in both non-infected and infected animals. The histology of the spleen, thymus and small intestine was similar in all three dietary groups before infection. The number of goblet cells per duodenal villus in vitamin A-deficient animals was significantly lower than that of control and pair-fed animals. In the small intestine of vitamin A-deficient animals, rotavirus infection caused dramatic changes to the mucosa, with almost complete destruction of the tips of the villi, but control and pair-fed animals had normal villi. It is concluded that although rotavirus infection and vitamin A-deficiency cause few changes alone, in their action together there is significant destruction of the mucosal barrier of the small intestine.
\end{abstract}

Rotavirus: Vitamin A: Mouse model

Viruses are a major cause of diarrhoeal disease in infants and young children in both the developed and underdeveloped countries. Of the viruses associated with acute gastroenteritis, rotavirus is one of the most important, having been extensively implicated in seasonal outbreaks of diarrhoea (World Health Organization Scientific Working Group, 1980). Recurrent episodes of diarrhoea have been identified as a major cause of reduced growth in many areas of the world.

It has been claimed that globally vitamin A deficiency ranks amongst the most common of dietary deficiencies, with only total energy and protein deficiency being more prevalent (Roels, 1970). A number of reports have noted an association between vitamin A deficiency and an increased sensitivity to, or frequency of, bacterial, viral and protozoal infections (Bang \& Foard, 1971; Cohen \& Elin, 1974; Krishnan et al. 1976; Nauss et al. 1985a). However, although an association has been shown, the exact role of vitamin $\mathrm{A}$ is not yet clear, and the specific mechanisms that influence the host's susceptibility to infectious agents still remain to be elucidated.

It is known that vitamin A deficiency alters the growth and differentiation of epithelial tissues (Wolbach, 1954). As an infection with rotavirus acts at the level of the epithelium of the gut we considered it of interest to investigate the relationship between vitamin $A$ and rotavirus infection and hypothesized that there would be a specific interaction in the gastrointestinal tract. The present investigation was, therefore, designed to examine the impact of vitamin A deficiency on infection with rotavirus, using the mouse as a model. This system was chosen because the pathogenesis and clinical manifestations of rotavirus 
infection in the infant mouse are similar to rotavirus infection in the human infant (Cheever \& Mueller, 1947; Bishop et al. 1973). The studies were carried out at the earliest time at which definite vitamin A deficiency could be established in the mouse, between 12 and 15 weeks of age, and we examined the effect of vitamin A deficiency on the response of these animals to rotavirus infection.

\section{MATERIALS AND METHODS}

\section{Animals and diets}

Male Porton mice, from a locally bred colony, were received at weaning (20-21 d of age). They were housed in groups of two or three in plastic cages at a room temperature of $20 \pm 2^{\circ}, 50 \%$ humidity and a $12 \mathrm{~h}$ lighting schedule each day. The animals were fed on one of three diets formulated for the purpose of the present study. A control group was allowed access $a d$ lib. to a diet that provided a balanced nutrient intake. The deficient group was allowed access ad lib. to a diet that was deficient in vitamin A. A third group was allowed limited access to the control diet, being pair-fed to the intake of the deficient group on the previous day.

The deficient diet (Table 1), a vitamin A-free purified pelleted diet, prepared in our laboratory, supplied all other nutrients to the recommended level for the mouse (American Institute of Nutrition, 1977). The control and pair-fed diets were formulated in a similar way to the deficient diet, but contained added vitamin A (retinyl palmitate as stabilized powder) at $1.2 \mathrm{mg} / \mathrm{kg}$ diet. Food consumption was measured daily and body-weight was measured at weekly intervals.

\section{Experimental design}

The time-course of the development of a deficiency state was determined in a preliminary study. On the basis of body-weight, hepatic vitamin A content and plasma vitamin A concentration, biochemical and clinical vitamin A deficiency were apparent after 63-70 d on the deficient diet. On day 77 of the experimental diet, mice from each dietary group were subdivided into infected and non-infected groups and the infected animals were given $30 \mu \mathrm{l}$ EDIM rotavirus (contained $10^{4 \cdot 5} \mathrm{ID}_{50}$ )/mouse by oral dosing. This dose was chosen because it is sufficient to cause diarrhoea in infant mice fed on a balanced diet (Starkey et al. 1986). The potency of the stock virus was confirmed using infant mice, from the histopathological changes in the gut $48 \mathrm{~h}$ after infection.

On day 84 , animals were lightly anaesthetized by inhalation of Metophan for the collection of blood by heart puncture before death. The blood samples were centrifuged at $2000 \mathrm{~g}$ for $5 \mathrm{~min}$, and the serum separated and stored at $-20^{\circ}$. The thymus, spleen and liver were removed immediately after killing the animals, lightly blotted and weighed. A weighed specimen of each was stored at $-20^{\circ}$ for biochemical analysis, and portions of thymus, spleen and small intestine were fixed for histology.

\section{Analytical procedures}

Vitamin A in serum was measured by the spectrophotometric method of Bradley \& Hornbech (1973). The vitamin A was extracted from $100 \mu 1$ serum with $100 \mu \mathrm{l}$ ethanol and $500 \mu \mathrm{l}$ hexane. The carotene level in the top hexane layer was measured as the absorption at $450 \mathrm{~nm}$, and then the hexane was evaporated under a stream of nitrogen gas. The vitamin A extracted from serum was redissolved in chloroform and measured spectrophotometrically, using trifluoroacetic acid at $620 \mathrm{~nm}$.

Vitamin A in liver was measured by the method of Bayfield (1975), with modifications. In brief, the liver was homogenized in ethanol and the vitamin A extracted with hexane. 
Table 1. Composition of the vitamin A-deficient diet $(\mathrm{g} / \mathrm{kg})$

\begin{tabular}{lc}
\hline Component & Amount \\
\hline Vitamin-free casein* & $200 \cdot 0$ \\
Maize starch $\dagger$ & 455.0 \\
Sucrose & $200 \cdot 0$ \\
Cellulose $\ddagger$ & 50.0 \\
Maize oil\$ & 50.0 \\
Vitamin mix $\|$ & 10.0 \\
Mineral mix $\|$ & 35.0 \\
\hline
\end{tabular}

* Special diet services, Witham, Essex.

$\uparrow$ CPC product, Trafford Park, Manchester.

\$ Solka Floc, Johnson, Jorgensen and Wettre, Ltd, Wokingham, Berkshire.

$\S$ London Oil Medina, London.

I| Vitamin mixture $(\mathrm{mg} / \mathrm{kg})$ : thiamin hydrochloride 600 , riboflavin 600 , pyridoxine 700 , nicotinic acid 3000 , calcium pantothenate 1600 , folic acid 200 , biotin 20 , cyanocobalamin 1 , vitamin D (stabilized powder) 200 , vitamin $\mathrm{E}$ (stabilized powder) 10000 , menadione 5, inositol 10000 , choline 10000 , sucrose to make $1000 \mathrm{~g}$.

I Mineral mixture $(\mathrm{g} / \mathrm{kg})$ : $\mathrm{CaHPO}_{4} 500 \cdot 0, \mathrm{NaCl} 74 \cdot 0, \mathrm{KCl} 42 \cdot 0, \mathrm{~K}_{2} \mathrm{SO}_{4} 52 \cdot 0, \mathrm{Mg}(\mathrm{OH})_{2} 35 \cdot 0, \mathrm{MnCO}_{3}$ (manganese $42-46 \%$ ) 3.5, ferric citrate trihydrate (iron $18 \%$ ) 6.0, zinc carbonate $1 \cdot 6$, cupric carbonate (copper $53-55.5 \%) 0.3$, KI $0.01, \mathrm{Na}_{2} \mathrm{SeO}_{4} .10 \mathrm{H}_{2} \mathrm{O} 0.01$, chromium potassium sulphate. $12 \mathrm{H}_{2} \mathrm{O} 0.55$, sodium molybdate. $2 \mathrm{H}_{2} \mathrm{O} 0.01$, sucrose to make $1000 \mathrm{~g}$.

The top hexane layer was collected and evaporated. The vitamin A extracted was redissolved in choloroform and quantified spectrophotometrically, using trichloroacetic acid at $620 \mathrm{~nm}$.

\section{Histology}

Representative portions of spleen, thymus and small intestine were fixed in formaldehyde $(100 \mathrm{ml} / \mathrm{l})$ in phosphate-buffered saline $(9 \mathrm{~g}$ sodium chloride $/ 1$; PBS $)$. The tissues were embedded in paraffin. Sections, $4 \mu \mathrm{m}$ thickness, were stained with haematoxylin and eosin and examined under the light microscope.

\section{Immunocytochemical studies}

$\mathrm{B}$ and $\mathrm{T}$ lymphocytes of the spleen were stained using the immunoperoxidase technique of Nakane \& Pierce (1966). In brief, frozen sections of spleen were prepared with a cryostat. For B cells, sections were treated with rabbit anti-mouse Ig peroxidase conjugate (DAKO, Denmark). For $T$ cells, sections were treated with rat anti-mouse Pan-T (Nordic) followed by rabbit anti-rat peroxidase conjugate (Nordic). After washing all sections with Trisbuffered saline, the freshly prepared substrate, diaminobenzidine tetrahydrochloride (Sigma) solution in Tris-hydrochloric acid buffer with $1.0 \%$ hydrogen peroxide, was applied. The sections were then counter-stained with haematoxylin and differentiated with $1 \%$ acid alcohol, dehydrated and mounted.

The $\mathrm{T}$ and $\mathrm{B}$ cell areas were measured using the VIDS semi-automatic image analyser (Analytical Measuring System, Cambridge). All sections were measured under the same magnification and using the same calibration. The area of the field examined was the same throughout the experiment. The results were expressed as percentage of $B$ and $T$ cells, with the area of the field examined taken as $100 \%$.

\section{Mucin staining}

Representative portions of duodenum were fixed in formaldehyde in PBS and examined for mucus-secreting goblet cells by the method of Cook (1972). In brief, the tissues were embedded in paraffin. Sections ( $4 \mu \mathrm{m}$ thick) were cut longitudinally along the lumen of the 
gut and stained with Alcian Blue and Periodic Acid Schiff reagent. The goblet cells were scored only in those villi for which a complete, representative longitudinal section could be identified.

\section{Statistical analysis}

The results were expressed as means with their standard errors for each experimental group. Statistical significance was determined by the use of Student's $t$ test for parametric data (Bishop, 1971).

\section{RESULTS \\ Body-weight}

The average body-weight of the animals on the deficient diet was not different from that of the controls for the first $35 \mathrm{~d}$. However, at this point the growth curves of the two groups began to diverge, and by 63-70 d the deficient animals had ceased to gain weight (Fig. 1). In contrast the group pair-fed to the intake of the deficient animals continued to gain weight until the end of the study. Although the body-weight of the pair-fed group was less than that of the ad lib. fed group this difference did not reach statistical significance. The pair-fed animals ingested about $10 \%$ less food than the ad lib. controls after $63 \mathrm{~d}$ on their dietary schedule. At 11 weeks, when the animals were infected with rotavirus, there was a significant reduction in the body-weight of the vitamin A-deficient group compared with the ad lib. $(P<0.01)$ or pair-fed $(P<0.05)$ animals. There was no significant change in body-weight following rotavirus challenge in any of the dietary groups.

\section{Vitamin A levels}

Although cessation in weight gain was a useful sign of the development of a deficiency state, biochemical confirmation was sought by measuring the amount of vitamin $A$ in liver and serum with time. The vitamin A concentration in liver after 12 weeks on the diet did not differ between control and pair-fed animals (Table 2). There was, however, a significant reduction in liver vitamin $\mathrm{A}$ in the animals on the deficient diet $(P<0.001)$ compared with both groups on the control diet. Infection with rotavirus was not seen to have any specific effect on the vitamin A concentration within each dietary group. Serum vitamin A did not differ between control and pair-fed animals, but the animals given the deficient diet showed a significant reduction $(P<0.001)$.

\section{Organ weight}

The relative liver weight of the control, pair-fed and vitamin A-deficient groups were not different, and were not affected by infection with rotavirus (Table 3 ). There was no significant difference in the relative spleen weights amongst the different dietary groups of the non-infected animals. The changes brought about by infection were significantly different $(P<0.001)$ in the vitamin A-deficient animals, where there tended to be an increase, from those in the control and pair-fed groups, where there tended to be a decrease. The slight decrease in spleen weight in the pair-fed animals failed to reach statistical significance. The relative thymus weight was found to be significantly reduced in the vitamin A-deficient animals, and this difference persisted following infection with rotavirus.

\section{Histology}

Thymus. Despite the changes in the relative weight of the thymus of the vitamin A-deficient animals, there were no marked changes in thymus histology between any of the dietary groups studied. Both the cortex and medulla of the thymus appeared normal in the vitamin A-deficient group, and similar to those of the control and pair-fed animals.

Spleen. There was no observable difference in either the red pulp or the white pulp of any of the dietary groups in the non-infected state, and infection did not produce any noticeable 


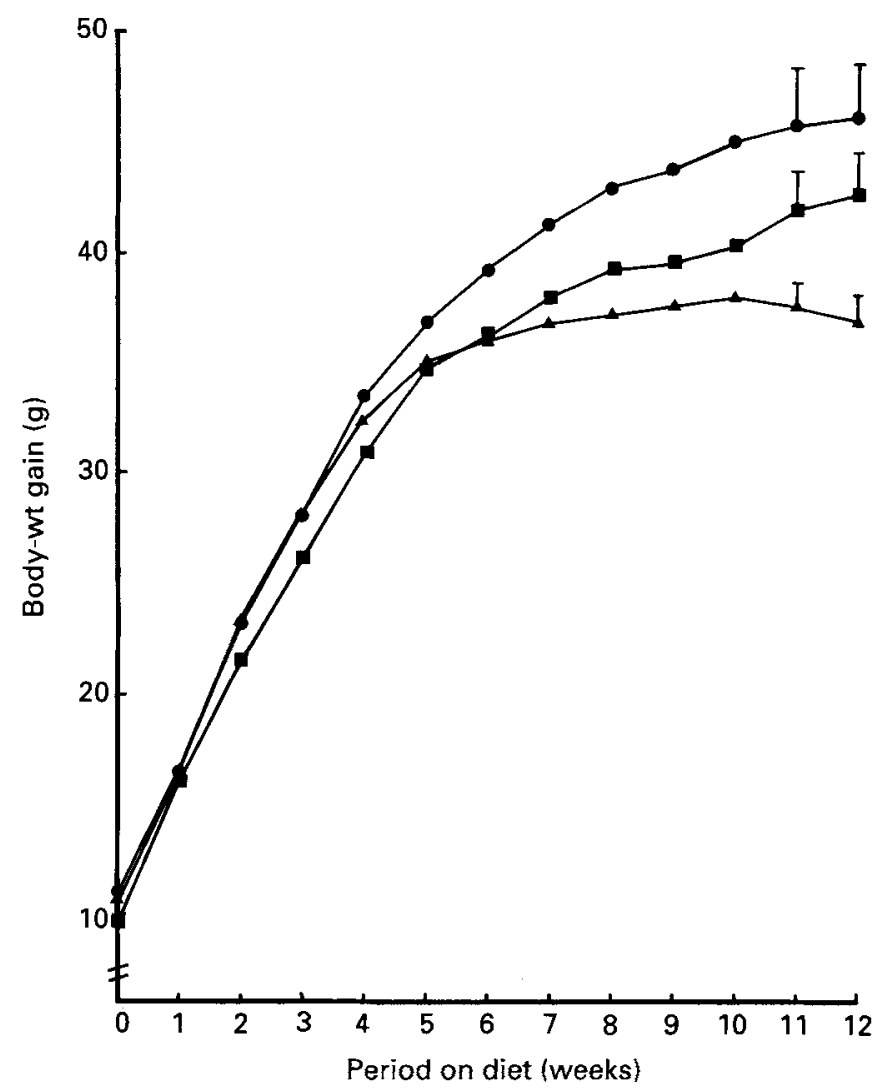

Fig. 1. The body-weights of mice fed on a control diet (-), a vitamin A-deficient diet $(\boldsymbol{\Delta}-\mathbf{A})$ or pair-fed on a control diet ( $-\square$ ) from weaning for 12 weeks. Each point represents the mean body-weight of eight mice; at 11 and 12 weeks standard errors of the means are represented by vertical bars.

Table 2. Effect of vitamin $A$ deficiency and rotavirus infection on liver and serum vitamin A levels of mice

(Mean values with their standard errors for three non-infected and five infected mice)

\begin{tabular}{|c|c|c|c|c|c|c|}
\hline \multirow{3}{*}{$\begin{array}{l}\text { Treatment } \dagger \ldots \\
\text { Dietary group } \dagger\end{array}$} & \multicolumn{4}{|c|}{ Liver $(\mu \mathrm{g} /$ liver $)$} & \multirow{2}{*}{\multicolumn{2}{|c|}{$\frac{\operatorname{Serum}(\mu \mathrm{g} / \mathrm{l})}{\text { Non-infected }}$}} \\
\hline & \multicolumn{2}{|c|}{ Non-infected } & \multicolumn{2}{|c|}{ Infected } & & \\
\hline & Mean & SEM & Mean & SEM & Mean & SEM \\
\hline Control & $238 \cdot 0$ & 90 & $250 \cdot 0$ & $13 \cdot 0$ & 435 & 35 \\
\hline Pair-fed & 216.0 & 80 & $221 \cdot 0$ & 13.0 & 406 & 20 \\
\hline Deficient & $0.5^{* * *}$ & 0.1 & $0 \cdot 5^{* * *}$ & 0.1 & $46^{* * *}$ & 8 \\
\hline
\end{tabular}

Mean values were significantly different from those for control and pair-fed groups $(t$ test $):{ }^{* *} P<0 \cdot 001$.

+ For details, see p. 364.

changes. Similarly there were no changes in the B cell area of the non-infected group. In contrast, the B cell areas of the vitamin A-deficient animals following infection appeared larger than those of the corresponding control or pair-fed animals. It seems that in infected vitamin A-deficient animals the spleen had more follicles than in the other groups.

Gut. The histology of the middle portion of the small intestine was examined by light 
Table 3. Effect of vitamin A deficiency and rotavirus infection on relative organ weights of mice

(Mean values with their standard errors for three non-infected and five infected mice)

\begin{tabular}{|c|c|c|c|c|c|c|c|}
\hline \multirow[b]{2}{*}{ Dietary group $\dagger$} & \multirow[b]{2}{*}{ Treatment $\dagger$} & \multicolumn{2}{|c|}{$\begin{array}{c}\text { Liver } \\
(\mathrm{g} / \mathrm{kg} \text { body-wt) }\end{array}$} & \multicolumn{2}{|c|}{$\begin{array}{c}\text { Spleen } \\
(\mathrm{g} / \mathrm{kg} \text { body-wt) }\end{array}$} & \multicolumn{2}{|c|}{$\begin{array}{l}\text { Thymus } \\
\text { (g/kg body-wt) }\end{array}$} \\
\hline & & Mean & SEM & Mean & SEM & Mean & SEM \\
\hline Control & $\begin{array}{l}\text { Non-infected } \\
\text { Infected }\end{array}$ & $\begin{array}{l}43 \\
37\end{array}$ & $\begin{array}{l}1 \\
2\end{array}$ & $\begin{array}{l}2 \cdot 4 \\
2 \cdot 1\end{array}$ & $\begin{array}{l}0 \cdot 2 \\
0 \cdot 1\end{array}$ & $\begin{array}{l}1 \cdot 1 \\
1 \cdot 0\end{array}$ & $\begin{array}{l}0 \cdot 1 \\
0 \cdot 1\end{array}$ \\
\hline Pair-fed & $\begin{array}{l}\text { Non-infected } \\
\text { Infected }\end{array}$ & $\begin{array}{l}40 \\
38\end{array}$ & $\begin{array}{l}5 \\
1\end{array}$ & $\begin{array}{l}2 \cdot 9 \\
2 \cdot 2\end{array}$ & $\begin{array}{l}0 \cdot 3 \\
0 \cdot 1\end{array}$ & $\begin{array}{l}1 \cdot 1 \\
1 \cdot 1\end{array}$ & $\begin{array}{l}0.01 \\
0.04\end{array}$ \\
\hline Deficient & $\begin{array}{l}\text { Non-infected } \\
\text { Infected }\end{array}$ & $\begin{array}{l}39 \\
41\end{array}$ & $\begin{array}{l}2 \\
2\end{array}$ & $\begin{array}{l}3 \cdot 7 \\
4 \cdot 6 * *\end{array}$ & $\begin{array}{l}0.5 \\
0.4\end{array}$ & $\begin{array}{l}0 \cdot 9^{*} \\
0 \cdot 7^{* *}\end{array}$ & $\begin{array}{l}0.03 \\
0.05\end{array}$ \\
\hline
\end{tabular}

Mean values were significantly different from those for corresponding control and pair-fed groups ( $t$ test): $* P<0.05 ;{ }^{* *} P<0.01$.

$\dagger$ For details, see p. 364 .

microscopy. Care was taken to ensure that the histology of the small intestine was compared at similar sites for the different groups of animals. There was no difference in the villous pattern of the small intestine from the control, pair-fed or deficient animals in the non-infected groups. Following infection the villi of the control and pair-fed groups appeared normal, but there were marked changes for vitamin A-deficient animals. In fact, we observed that four of five infected vitamin A-deficient animals had destroyed villous tips and the lamina propria of the villous core was exposed to the lumen of the small intestine. One of the vitamin A-deficient animals had normal villous tips. On the other hand, in the control and pair-fed groups, four animals in each group appeared to have perfectly normal villous tips and regular-shaped villi, similar to non-infected animals. One animal from the control and one from the pair-fed group showed slight disarrangement of the tips of the villi; however, damage was less severe than was seen in the deficient animals. In vitamin A deficiency infection with rotavirus almost completely destroyed the tip of the villi, as shown in Plate 1. This effect was not seen in any of the non-infected animals, nor in the infected groups on a balanced intake, indicating a specific interaction of infection and vitamin A deficiency at the level of the gastrointestinal villus.

\section{$B$ and $T$ cell areas}

Since on histological examination the spleens of infected vitamin A-deficient animals appeared different from those of corresponding control and pair-fed groups, we decided to measure the areas of immuno-stained $B$ and $T$ cells in the spleen of the infected groups. The results obtained for comparative $B$ and $T$ cell areas in the spleen section are shown in Table 4. The B cell areas of vitamin A-deficient animals were found to be greater than those of the pair-fed controls, although the difference was not statistically significant. Also there were no significant changes in the $\mathrm{T}$ cell areas of infected vitamin-deficient animals compared with the pair-fed group. In both cases we used only their pair-fed group for comparison as there was no apparent histological difference between the control and pairfed spleens.

During the preparation of the spleen for sectioning, the lymphoid sheaths were cut along different axes. Some were in longitudinal section and some in transverse section. Thus to represent the result as a percentage of $\mathrm{B}$ cells or $\mathrm{T}$ cells may led to an error in the 
Table 4. Effect of vitamin $A$ deficiency and rotavirus infection on the $B$ and $T$ cell areas in the spleen of mice

(Mean values with their standard errors for five animals in each group)

\begin{tabular}{|c|c|c|c|c|c|c|}
\hline \multirow[b]{2}{*}{ Dietary group ${ }^{\dagger}$} & \multicolumn{2}{|c|}{$\begin{array}{c}\text { B cell area } \\
(\%)\end{array}$} & \multicolumn{2}{|c|}{$\begin{array}{c}\text { T cell area } \\
(\%)\end{array}$} & \multicolumn{2}{|c|}{ B:T cell ratio } \\
\hline & Mean & SEM & Mean & SEM & Mean & SEM \\
\hline Pair-fed & $33 \cdot 0$ & 1.2 & $19 \cdot 1$ & $3 \cdot 0$ & 1.9 & $0 \cdot 3$ \\
\hline Deficient & 40.9 & $4 \cdot 1$ & $13 \cdot 9$ & $2 \cdot 1$ & $3 \cdot 3$ & 0.6 \\
\hline
\end{tabular}

Differences not significant $(t$ test).

$\uparrow$ For details, see p. 364

Table 5. Effect of vitamin A deficiency and rotavirus infection on the intestinal goblet cells of mice

(Mean values with their standard errors for three non-infected mice and five infected mice. Twenty to forty villi in each sample were examined depending upon the availability of longitudinal sections of the villi)

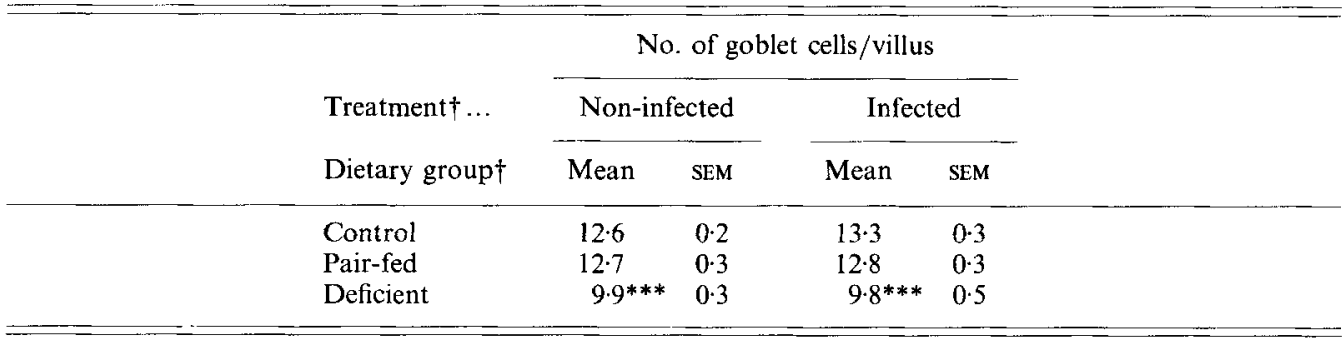

Mean values were significantly different from those for control and pair-fed groups $(t$ test $): * * * P<0 \cdot 001$.

+ For details, see p. 364.

conclusions. Therefore, we expressed our results in terms of B:T cell ratio, which may be more reliable. Although the B:T cell ratios of infected vitamin A-deficient animals were higher than those of their pair-fed group, the difference was not significant.

\section{Goblet cell count}

The counting of goblet cells along the villus is a difficult and tedious task. Great care was taken to take sections from comparable levels of the duodenum and include only those villi in which a full longitudinal section was available. For any single animal all the villi available from a single section were included in the count. On average it was possible to identify twenty to forty villi per section. In the non-infected animals the number of goblet cells per villus were significantly lower in the vitamin A-deficient animals than either the control or pair-fed groups, as shown in Table 5. Following infection, the number of goblet cells remained unchanged in the control and the pair-fed groups, with a similar degree of reduction in the deficient animals. More specific staining for neutral or acid mucin (values not shown) gave comparable results.

\section{DISCUSSION}

Rotavirus, one of the major causes of viral diarrhoea in infants and children throughout the world (World Health Organization Scientific Working Group, 1980), acts at the 
epithelium of the intestine (Starkey et al. 1986). Since vitamin A is an essential nutrient for the maintenance of the epithelia of various organs (Olson, 1972), we decided to investigate the relationship between vitamin A deficiency and diarrhoeal disease using rotavirus in an experimental animal. To the best of our knowledge this is the first investigation of the interaction of vitamin A deficiency and rotavirus infection.

It is surprisingly difficult to produce vitamin A deficiency in laboratory mice (McCarthy \& Cerecedo, 1952; Smith et al. 1987). McCarthy \& Cerecedo (1952) have shown that in weanling mice symptoms of vitamin A deficiency appeared after $90-120 \mathrm{~d}$ of feeding. However, these authors used ordinary casein in their diet, which may contribute exogenous vitamin A. Particular care has to be taken to ensure that the individual components of the diet do not introduce significant quantities of vitamin A. By using vitamin A-free casein and oil we were able to produce a vitamin A-deficient model using weanling mice. There is a direct relationship between the rate of vitamin A utilization and growth rate (Rechcigl et al. 1962), and so we considered that the virtual cessation of weight gain after 9-10 weeks on the diet was a reasonable indication of a vitamin A-deficient state. Smith et al. (1987) reported that giving a vitamin A-deficient diet to pregnant females during the 2 nd week of gestation and continuing to feed their offspring on the same diet produces vitamin Adeficient mice at 8 weeks of age. Others have found that the exact timing of the onset of the plateau of weight gain might vary. A time range of $40-60 \mathrm{~d}$ appears general, and differences might reasonably be accounted for by variations in liver reserves, other aspects of the diet, or other environmental factors that vary between laboratories (Bieri, 1969; Muto et al. 1972; Takagi \& Nakano, 1983; Nauss et al. 1985 b). A severe deficiency state in the experimental animals was confirmed by the demonstration of severely reduced concentrations of both hepatic and serum vitamin A. More recently we have been able to measure vitamin A levels by high-performance liquid chromatography, and find that the levels in a vitamin A-deficient group appear even lower than those reported in the present paper.

In the present study, the experimental protocol was completed within $84 \mathrm{~d}$ of giving the experimental diet. During this period demonstrable clinical symptoms were not seen, other than the body-weight plateau. There was no opportunistic infection. It is possible that the development of clinical symptoms of vitamin A deficiency in an individual requires an additional metabolic stress or complications such as an infection. Bieri (1969) has demonstrated that germ-free vitamin A-deficient rats continued to gain weight for a longer period of time than conventional vitamin A-deficient animals. In fact an important aspect of our study was that the vitamin A-deficient animals had no signs of intercurrent infection as judged by the histology of the gut and spleen. Thus, we have been able to demonstrate the effect of rotavirus infection as a primary event in vitamin A-deficient mice.

Although the absolute and relative weight of the thymus was significantly reduced in both the non-infected and infected vitamin A-deficient animals, we did not see any histological changes in the thymus of any of the experimental groups, nor were we able to identify histological changes in the spleen. These findings are at variance with those found in rats by Krishnan et al. (1974), who observed marked involution of the germinal centres of the spleen, and depletion of lymphocytes in the thymic cortex of vitamin A-deficient animals. However, these workers also reported similar changes in their pair-fed animals, implying that the changes described cannot be attributed to the specific effects of vitamin A deficiency itself, but are non-specific, being more closely related to the degree of general inanition.

The significant difference in relative spleen weight in the infected animals shown in Table 3 between the deficient group on the one hand and the control and pair-fed groups on the other arises from a combination of changes associated with infection, a non-significant 
decrease in the pair-fed and control groups and a non-significant increase in the deficient group. An apparent increase in the number of splenic germinal centres in infected vitamin A-deficient animals was observed compared with control and pair-fed animals. However, we could not demonstrate this increase by measuring the $B$ and $T$ cell areas following immunostaining. In practice it is very difficult to measure representative sections from all spleen samples. In an attempt to quantify the apparent difference, the results were also expressed as a B:T cell ratio. Although there was a trend towards a higher B:T cell ratio in the vitamin A-deficient mice the difference did not reach statistical significance. The spleen weight of vitamin A-deficient infected animals was higher than in the control and pair-fed groups. Taken together with the finding of obvious damage to the integrity of the intestinal mucosa, we consider that this might represent indirect evidence for greater effective systemic exposure of the deficient, infected animals to rotavirus challenge.

The most extensive changes were seen in the histology of the small intestine in the vitamin A-deficient animals following infection with rotavirus. In the non-infected animals there was no significant difference between the control, deficient or pair-fed groups. Following infection the control and pair-fed groups remained unchanged, but in the deficient group the mucosal integrity was extensively disrupted. It has been reported that rotavirus specifically infects the cells in the upper two-thirds of the villus in infant mice and the structural changes are confined to the small intestine, with the middle portion showing the most pronounced changes (Starkey et al. 1986). Furthermore, no pathological changes were reported in the colon of these mice (Starkey et al. 1986). For this reason we examined the middle portion of the small intestine and our findings would suggest that vitamin $\mathrm{A}$ deficiency increases the susceptibility of these cells to damage by rotavirus. Vitamin A deficiency of itself would appear to be insufficient to produce severe damage alone, but does impair the cells' ability to withstand other pathological agents.

None of the animals had diarrhoea following rotavirus challenge. It may be a general phenomenon that agents which produce small bowel diarrhoea in infants are much less likely to do so in more mature animals. Argenzio et al. (1984) have shown the development of colonic function with age ensures that in the older animal increased fluid absorption by the large bowel means that clinical diarrhoea is not seen in pigs following infection with corona virus, whereas it is obvious in neonatal animals.

The mucous barrier of the gastrointestinal tract represents one component of the nonspecific immune system which has been shown to be sensitive to vitamin A status (Rojanapo et al. 1980). Rojanapo et al. (1980) found that in rats the number of mucussecreting cells in the duodenal crypt could be reduced by $40 \%$ in vitamin A deficiency, which compares with the reduction of $25 \%$ that we have shown for the duodenal villus of the mouse. The same group found that the functional activity of the remaining goblet cells appeared to be normal, which led to the suggestion that vitamin A deficiency resulted in the loss of a subpopulation of goblet cells which subserve a specific function (Rojanapo et al. 1980). Indeed, at the biochemical level it would seem that the synthesis of a particular glycoprotein is affected by the vitamin A deficiency (De Luca et al. 1970). In our study, more specific staining showed that there was a similar decrease in the number of goblet cells stained for acid or neutral mucin in the deficient animals, in agreement with observations made in the rat. Taken together with the marked histological changes seen in the mucosa of the deficient animals infected with rotavirus, we have demonstrated an association between a reduced number of goblet cells and more severe local damage, which may indicate an important protective role for the mucin. This observation introduces a further complication to the experimental model. If the mucous barrier is effective in limiting the infective load seen by the cells of the villous tip, then the systemic infective challenge would vary between the animals on the deficient and control diets. 
In most of the earlier studies in which the interaction of vitamin A deficiency and immune responsiveness has been explored, the infective challenge has been given by the parenteral route. In the present study we have shown that the non-specific mucosal barrier of the gastrointestinal tract can be severely impaired by vitamin A deficiency, but that this damage may only become obvious in the face of an infective challenge. This finding has general importance for the study of the interaction of vitamin A deficiency and infection, as any group of vitamin A-deficient animals are likely to be continuously exposed to a higher level of environmental challenge, through a weakened mucosal barrier, than animals fed on a standard diet.

The role of vitamin $\mathrm{A}$ in immunity may reside in its protective action at more than one level. The mucous barrier of the gastrointestinal tract represents one component of the nonspecific immune system which has been shown to be sensitive to vitamin A status. We also have evidence for changes in the specific immunity in vitamin A deficiency following oral challenge of rotavirus, which will be the subject of a subsequent report.

The authors thank the Commonwealth Scholarship Commission, London for their financial support for this study. They also thank Dr Starkey and his colleagues, Department of Microbiology, University of Birmingham for supplying the EDIM rotavirus strain. This work was supported in part by a grant from the Wessex Medical School Trust.

\section{REFERENCES}

American Institute of Nutrition (1977). Report of the American Institute of Nutrition ad hoc Committee on standards for nutritional studies. Journal of Nutrition 107, 1340-1348.

Argenzio, R. A., Moon, H. W., Kemeny, L. J. \& Whipp, S. C. (1984). Colonic compensation in transmissible gastroenteritis of swine. Gastroenterology 86, 150l-1509.

Bang, F. B. \& Foard, M. A. (1971). The effect of acute vitamin A deficiency on the susceptibility of chicks to Newcastle disease and influenza viruses. Johns Hopkins Medical Journal 129, 100-109.

Bayfield, R. F. (1975). Simplified methods for the examination of liver lipids. 1. Determination of vitamin A in liver using a direct solvent extraction technique. Analytical Biochemistry 64, 403-413.

Bieri, J. G. (1969). Comments. American Journal of Clinical Nutrition 22, 1086-1087.

Bishop, O. N. (1971). Statistics for Biology, 2nd ed., pp. 46-55. London: Longman Group.

Bishop, R. F., Davidson, G. P., Holmes, I. H. \& Ruck, B. J. (1973). Virus particles in epithelial cells of duodenal mucosa from children with acute non-bacterial gastroenteritis. Lancet ii, 1281-1283.

Bradley, D. W. \& Hornbech, C. L. (1973). A clinical evaluation of an improved TFA micromethod for plasma and serum vitamin A. Biochemical Medicine 7, 78-86.

Cheever, F. S. \& Mueller, J. H. (1947). Epidemic diarrhoeal disease of suckling mice. I. Manifestations, epidemiology and attempts to transmit the disease. Journal of Experimental Medicine 85, 405-416.

Cook, H. C. (1972). Demonstration procedures. In Human Tissue Mucins, pp. 18-19 [F. J. Baker, editor]. London: Butterworth.

Cohen, B. E. \& Elin, R. J. (1974). Vitamin A-induced nonspecific resistance to infection. Journal of Infectious Diseases 129, 597-600.

De Luca, L., Schumacher, M. \& Wolf, G. (1970). Biosynthesis of a fucose-containing glycopeptide from rat small intestine in normal and vitamin A deficient conditions. Journal of Biological Chemistry 245, 4551-4558.

Krishnan, S., Bhuyan, U. N., Talwar, G. P. \& Ramalingaswami, V. (1974). Effect of vitamin A and protein-calorie undernutrition on immune response. Immunology 27, 383-392.

Krishnan, S., Krishnan, A. D., Mustafa, A. S., Talwar, G. P. \& Ramalingaswami, V. (1976). Effect of vitamin A and undernutrition on the susceptibility of rodents to a malarial parasite Plasmodium berghei. Journal of Nutrition 106, 784-791.

McCarthy, P. T. \& Cerecedo, L. R. (1952). Vitamin A deficiency in the mouse. Journal of Nutrition 46, 361-376.

Muto, Y., Smith, J. E., Milch, P. O. \& Goodman, DeW. S. (1972). Regulation of retinol-binding protein metabolism by vitamin A status in the rat. Journal of Biological Chenistry 247, 2542-2550.

Nakane, P. K. \& Pierce, G. B. Jr (1966). Enzyme labeled antibodies: preparation and application for the localization of antigen. Journal of Histochemistry and Cytochemistry 14, 929-93I.

Nauss, K. M., Anderson, C. A., Conner, M. W. \& Newberne, P. M. (1985a). Ocular infection with Herpes Simplex Virus (HSV-1) in vitamin A-deficient and control rats. Journal of Nutrition 115, 1300-1315.

Nauss, K. M., Phua, C. C., Ambrogi, L. \& Newberne, P. M. (1985 b). Immunological changes during progressive stages of vitamin A deficiency in the rat. Journal of Nutrition 115, 909.918. 

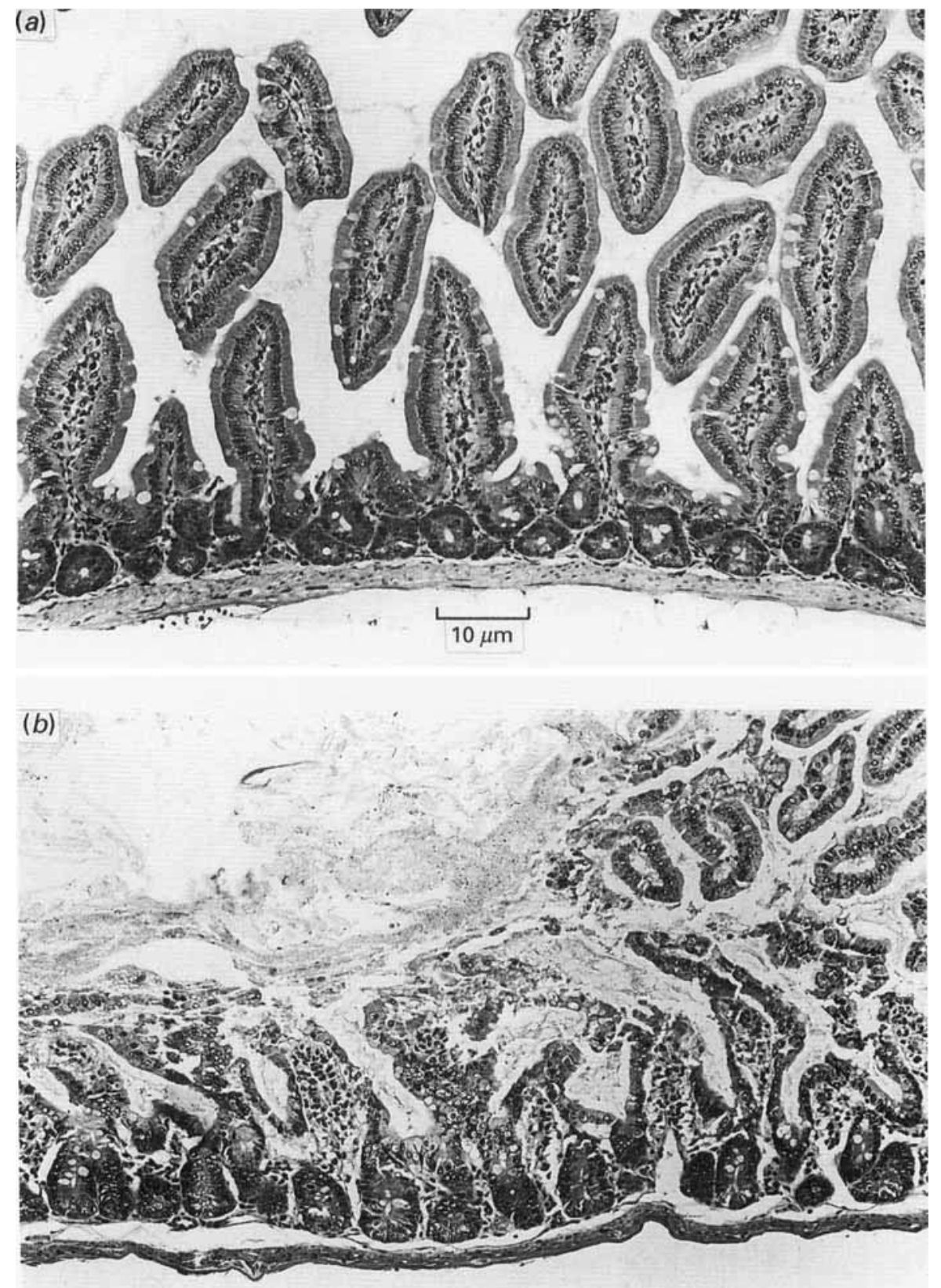

EXPLANATION OF PLATE

Plate 1. Longitudinal sections stained with haemotoxylin and eosin $(\times 120)$ of the small intestine from $(a)$ control and (b) vitamin A-deficient mice $7 \mathrm{~d}$ after an oral challenge with rotavirus. In the deficient animals there is extensive disruption of the villus architecture. 
Olson, J. A. (1972). The biological role of vitamin A in maintaining epithelial tissues. Israel Journal of Medical Sciences 8, 1170-1178.

Rechcigl, M. Jr, Berger, S., Loosli, J. K. \& Williams, H. H. (1962). Dietary protein and utilization of vitamin A. Journal of Nutrition 76, 435-440.

Rojanapo, W., Lamb, A. J. \& Olson, J. A. (1980). The prevalence, metabolism and migration of goblet cells in rat intestine following the induction of rapid, synchronous vitamin A deficiency. Journal of Nutrition 110 , 178-188.

Roel, O. A. (1970). Vitamin A physiology. Journal of the American Medical Association 214, $1097-1102$.

Smith, S. M., Levy, N. S. \& Hayes, C. E. (1987). Impaired immunity in vitamin A deficient mice. Journal of Nutrition 117, 857-865.

Starkey, W. G., Collins, J., Wallis, T. S., Clarke, G. J., Spencer, A. J., Haddon, S. J., Osborne, M. P., Candy, D. C. A. \& Stephen, J. (1986). Kinetics, tissue specificity and pathological changes in murine rotavirus infection of mice. Journal of General Virology 67, 2625-2634.

Takagi, H. \& Nakano, K. (1983). The effect of vitamin A depletion on antigen-stimulated trapping of peripheral lymphocytes in local lymph nodes of rats. Immunology 48, 123-128.

Wolbach, S. B. (1954). Effects of vitamin A deficiency and hypervitaminosis. In The Vitamins, vol. 1, pp. 106-137 [W. H. Sebrell and R. S. Harris, editor]. New York: Academic Press.

World Health Organization Scientific Working Group (1980). Rotavirus and other viral diarrhoeas. WHO Bulletin no. 33. Geneva: WHO. 